\title{
ESPACIALIDADE E MASCULINIDADE NA VIVÊNCIA DE JOVENS DA ESCOLA DE 'GUARDAS MIRINS' EM PONTA GROSSA, PARANÁ
}

\section{SPATIALITY AND MASCULINITY ON EXPERIENCES OF YOUNG FROM SCHOOL 'JUNIOR GUARDS' IN PONTA GROSSA, PARANÁ}

\author{
João Paulo Leandro de Almeida \\ Geógrafo - Grupo de Estudos Territoriais \\ Universidade Estadual de Ponta Grossa \\ jpl_almeida@yahoo.com.br \\ Marcio Jose Ornat \\ Doutor em Geografia - Grupo de Estudos Territoriais \\ Universidade Estadual de Ponta Grossa \\ geogenero@gmail.com
}

\begin{abstract}
RESUMO
Esta discussão tem por objetivo compreender a relação entre espacialidades e a constituição de masculinidades de jovens no cotidiano da Escola de Guardas Mirins 'Tenente Antônio João', na cidade de Ponta Grossa, Paraná. Esta reflexão tem por referencial as informações cadastrais institucionais de 203 discentes matriculados, da lista de 1.723 candidatas e candidatos a vagas nesta instituição e do resultado da realização de 10 entrevistas semiestruturas com alunos entre 14 a 16 anos. Tal material empírico evidencia, segundo imbricações entre militarismo e espiritismo kardecista, relações entre vivências espaciais e construções de masculinidades em homens jovens. Da mesma forma que existem várias feminilidades, é cabível que existam múltiplas masculinidades, não estritamente orientadas a uma direção do que é ser homem. Os alunos da Escola de Guardas Mirins 'Tenente Antônio João' são uma destas possibilidades, fenômeno este que dialoga cotidianamente com construções de masculinidade hegemônicas e periféricas.
\end{abstract}

Palavras-Chave: Espaço; Masculinidade; Geografia Feminista; Escola de Guardas Mirins.

\begin{abstract}
This discussion aims to understand the relationship between spatiality and the constitution of masculinities in youth in school of the Mirins Guards 'Tenente Antônio João', Ponta Grossa city, Paraná. The empirical material refers institutional registration information of 203 students enrolled, the list of 1.723 candidates and candidates for vacancy in this institution and the outcome of 10 interviews with students aged 14 to 16 years. We evidenced a relationship between militarism and the spiritualism (kardecist), relationship between spatial living and the building of the masculinities in youth men. Likewise there are several femininity, it is reasonable that there are multiple masculinities, not strictly oriented in a direction of being a man. Students of the Mirins Guards 'Tenente Antônio João', Ponta Grossa city, are this possibilities, Students of the School of the Mirins Guards 'Tenente Antônio João', Ponta Grossa city, are this
\end{abstract}


possibilities, phenomenon that dialogues with hegemonic constructions and peripheral of the masculinities.

Keywords: Space; Masculinity; Feminist Geography; School of the Mirins Guards.

\section{Considerações Iniciais}

Esta discussão tem por objetivo compreender a relação entre espacialidades e a constituição de masculinidades de jovens no cotidiano da Escola de Guardas Mirins 'Tenente Antônio João', na cidade de Ponta Grossa, Paraná. Sendo produzido no âmbito do Grupo de Estudos Territoriais, esta reflexão tem por referencial as informações cadastrais institucionais de 203 discentes matriculados, da lista de 1.723 candidatas e candidatos a vagas nesta instituição e do resultado da realização de 10 entrevistas semiestruturas com alunos entre 14 a 16 anos.

Fundada por Epaminondas Xavier de Barros, em 14 de julho de 1965, foi a primeira unidade departamental do Instituto Educacional Duque de Caxias, contando atualmente com creches, escolas e casas de apoio familiar, atendendo a pessoas com baixo poder aquisitivo. O Sr. Barros, como conhecido, retirou 15 meninos menores que estavam detidos na 'Cadeia Pública' da cidade, com o objetivo de lhes dar formação e reintegração à sociedade. Inicialmente, o que era um regime de internato transformou-se em uma atividade de contra turno escolar.

Esta instituição coloca-se como referencial de reflexão devido ao fato de que possui em atividade de contra turno alunos e alunas, submetidos a hierarquia pré-militar - que vai do aprendiz mirim ao comandante - metodologia esta de educação constituída pelo treino da força, da disciplina, do respeito à hierarquia, elementos estes apontados por Hale (2012) como constituidores de formas de masculinidade. A reflexão sobre espaço e masculinidade, já consolidada na produção geográfica anglofóna, como evidenciado por Silva e Ornat (2011), coloca-se na Geografia Brasileira ainda como insipiente. Frente a esta situação, valiosas contribuições podem ser visualizadas em Chimin Junior (2009; 2011), Rossi (2010; 2011), Furlong (2011), Ratts (2011), Costa (2011), Gomes (2013) e Rocha (2013). Assim, os estudos sobre múltiplas masculinidades constituem-se enquanto um desafio à Geografia Brasileira.

A experiência vivenciada como guarda mirim por um dos pesquisadores deste

texto colaborou na compreensão da lógica da relação entre espacialidades e a 
constituição de masculinidades de jovens que experienciam cotidianamente esta instituição, na reaproximação com as suas práticas espaciais cotidianas. Assim, os elementos que constituíram esta posicionalidade específica, como tratado por Rose (1997), propiciaram a aproximação do grupo eleito para a discussão, facilitando a coleta de informações, tanto quantitativas como qualitativas. O recorte empírico da discussão esteve fundamentado na proposta de que este é uma construção intelectual que nasce do encontro fenomenal entre sujeito pesquisador e pesquisado.

A posicionalidade constitui o recorte empírico desta pesquisa, situação esta que permitiu o aprofundamento da produção de inteligibilidade do fenômeno a ser investigado. Esta posicionalidade específica enquanto ex-guarda mirim potencializou a vivência junto ao grupo, pois as respostas de campo em um trabalho investigativo devem sempre ser analisadas enquanto o resultado de processos de retro-alimentação entre os vários elementos que constituem a produção do conhecimento científico. De certa forma, a posição de 'veterano' na instituição avalizou a entrada junto ao grupo de jovens alunos, que como consequência, legitimou a realização das questões estabelecidas. A posição de outsider não existiu no processo de construção do campo, mas sim a de um participante veterano daquelas práticas que agora são problematizadas.

No tocante aos levantamentos quantitativos, inicialmente os dados referentes a lista de candidatos a vagas foi organizada em Banco de Dados Base que continha as informações do candidato, características familiares e motivo da solicitação da vaga. Em relação aos dados quantitativos das alunas e alunos ativos na instituição, os dados também alimentaram a organização de Banco de Dados Base com os elementos referentes as informações do aluno, características familiares, características da residência e encaminhamento de matrícula, esta última na situação em que o aluno fora encaminhado à instituição pelo Conselho Tutelar.

Sobre o levantamento qualitativo, a realização de entrevistas em profundidade produziu um total de 4 horas e meia de fala, que foram sistematizadas segundo a proposta de Bardin (1977), referente a análise de conteúdo do discurso. Para a autora, esta análise fundamenta-se na compreensão da comunicação, na articulação do texto, descrito e analisado segundo os fatores que determinaram suas características. Esta técnica refere-se ao desmembramento de partes do texto, denominadas de evocações, trechos estes que tem sentido específico no conjunto da fala. A partir de nossa 
perspectiva geográfica, em um segundo momento estes trechos foram classificados segundo espacialidades discursivas e categorias discursivas. Em relação a esta discussão, este processo de análise produziu um total de 268 evocações que foram classificadas segundo as espacialidades discursivas da 'Casa', 'Escola', 'Espaços de Sociabilidade', 'Guarda Mirim' e 'Igreja', constituídos por suas respectivas categorias discursivas.

Assim, para o desenvolvimento deste texto, inicialmente problematizamos a relação entre masculinidades, homens jovens e espaço. Em seguida, construímos uma discussão sobre a constituição de vivências espaciais, atravessadas transversalmente pelos elementos constituidores das masculinidades aos alunos jovens da Escola de Guardas Mirins 'Tenente Antônio João', na cidade de Ponta Grossa, Paraná. Como existem várias feminilidades, é cabível que possam existir várias masculinidades, não apenas aquela relacionada a um perfil de homem. É sobre estas possibilidades que este texto versa.

\section{Masculinidades, Homens Jovens e Espaço}

A humanidade em sua diversidade não despertou o interesse do conhecimento geográfico brasileiro. Esta situação demanda, como apontado por Souza (2011), a adoção de uma outra mentalidade, que é maior que opção teóricas ou metodológicas específicas. Para este autor, faz-se necessário o comprometimento com um pluralismo temático, superando a heteronomia temática. Devemos ir em direção a heterotopias epistêmicas, parafraseando a proposta de Foucault (1984), ou segundo a proposição de Mignolo (2004), contribuindo na produção do conhecimento científico a partir de outra lógica, relacionadas ao pensamento de fronteira, segundo diversidades pluritópicas.

Em se tratando da Geografia, segundo Silva (2009), há grupos sociais, discursos e temáticas obscurecidas pelo que pode ser denominado enquanto um saber científico moderno, masculino, branco, heterossexual e eurocêntrico. Nesta caminho, os estudos de múltiplas masculinidades despertou pouco interesse de autores da Geografia brasileira.

Todavia, várias discussões tomam para si este desafio, problematizando geograficamente a temática das masculinidades. Na discussão de Chimin Junior (2009; 
2011), o autor disserta sobre as maneiras em que o espaço compõe a vulnerabilidade aos atos infracionais desenvolvidos por adolescentes do sexo masculino. Segundo uma interface muito produtiva, Rossi $(2010 ; 2011)$ disserta sobre a existência espacial cotidiana de adolescentes do sexo masculino em conflito com a lei, segundo a relação entre masculinidades e interseccionalidades. A imbricação entre sexualidades e masculinidades é tratada por Furlong (2011), quando este compreende as performances de gênero e sexualidade em vários locais na Zona Sul do Rio de Janeiro, segundo tolerâncias de classe e raça. A temática da sexualidade também é objeto de Ratts (2011), a partir do pensar a negritude, a masculinidade e o homoerotismo. Costa (2011) discute a prática da pesquisa geográfica, segundo elementos de posicionalidade, no tocante a produção de conhecimento de grupos de homens orientados sexualmente ao mesmo sexo. Em Gomes (2013) e Rocha (2013) a temática da juventude e a da masculinidade também é tema de reflexão. Enquanto o primeiro autor objetivou compreender a relação entre as espacialidades vivenciadas por jovens do sexo masculino e a morte por homicídio, o segundo compreendeu a instituição de espacialidades relacionadas ao uso de 'crack' por adolescentes do sexo masculino moradores de periferias, ambos na cidade de Ponta Grossa, Paraná. Como visto, várias são as possibilidades de discussão geográfica relacionadas a masculinidades, e mesmo que se coloquem em pequeno número, frente ao volume de produção geográfica anglófona, como sinalizado por Silva e Ornat (2011), elas são o indicativo da pertinência deste caminho de discussão para a Geografia brasileira.

Segundo Rossi (2011), o conceito de masculinidade pode ser compreendido enquanto um dos elementos que compõe a vivência dos homens, elemento este não apenas de diferenciação entre o $e u$ e o outro, mas também da relação entre o $e u$ e o outro, a partir de várias vivências espaciais, corporais, sexuais e assim por diante. Em Connell (1995), a masculinidade também se define segundo o embate entre as masculinidades, constituindo-se segundo relações de dominação enquanto subordinadas, cúmplices e marginais. A masculinidade hegemônica para o autor é um resultado de configurações de relações de poder, posicionando pessoas em relação as práticas de gênero. Vale lembrar que para o autor esta masculinidade hegemônica também é tensionada nas relações sociais cotidianas, elemento este que deve ser levado em consideração na construção de uma crítica à própria proposta do autor. 
Connell (1995) inicia sua discussão destacando as mudanças sociais nas práticas de masculinidade. Segundo o autor, as possibilidades de mudança nas relações de gênero nascem com os Movimentos de Liberação de mulheres, gays e homens nos anos 70. Vinte anos mais tarde, a mudança no pensamento referente ao gênero, conquistadas por tais movimentos, são irreversíveis.

A maior parte dos críticos, baseados na noção de papel masculino, acreditavam em certa 'crise da masculinidade' e está levaria a mudança, sendo a masculinidade aniquilada ou substituída por uma androgênia. Para Connell (1995), este pensamento apocalíptico, hoje raro, seria ingênuo. Nos anos 70, os papéis de gênero eram bem definidos ao serem relacionados ao trabalho. O conceito de 'papel masculino' demonstra-se para o autor fraco, por não permitir que observemos as complexidades no interior da masculinidade e suas múltiplas possibilidades.

Primeiramente devemos tratar do conceito de espaço proposto por Massey (2004; 2008), sendo que este é constituído por inter-relações, esfera da multiplicidade e sempre em construção. A masculinidade de uma pessoa é instituída em relações sociais, das quais ela a compõe. Podemos afirmar então que ela é maleável, de acordo com a composição das relações. Se considerarmos que cada indivíduo compõe uma variedade de relações e se posiciona de forma diferente nestas relações, então temos múltiplas masculinidades. Considerando que as relações mudam no decorrer do tempo, tanto sua composição quanto a hierarquia dos componentes, poderíamos então afirmar que as masculinidades se colocam também em contínua construção.

Connell e Messerschmidt (2013) procuram revelar isto ao analisar as aplicabilidades do termo 'masculinidade hegemônica', afirmando que não temos apenas a característica de diferenciação das masculinidades. Além deste elemento, as masculinidades estão sempre sujeitas a mudança, se desafiando ou se ajustando de acordo com a espacialidade e com as relações de poder que acontecem através desta. Os resultados colhidos em campo evidenciam esta configuração, tendo visto o fato de que a constituição das masculinidades de alunos jovens na Escola de Guardas Mirins 'Tenente Antônio João' estão sempre sujeitas a variadas mudanças. Elas colocam-se em diálogo, a partir de ajustes, ou mesmo no desafio do que é considerado pelo grupo enquanto uma masculinidade a ser desempenhada.

Outro componente da justificativa inicial de Connell (1995) refere-se ao corpo. 
Para o autor, "a masculinidade é uma configuração de práticas em torno da posição dos homens na estrutura das relações de gênero", havendo varias configurações desse tipo em qualquer ordem de gênero, envolvidas com as relações de poder em uma sociedade. Este autor justifica sua definição de gênero ao propor que "falar de posição dos homens significa enfatizar que a masculinidade tem haver com relações sociais e também se refere a corpos - uma vez que 'homens' significa pessoas adultas com corpos masculinos" (CONNELL, 1995 p. 188), fornecendo componentes importantes para efetuarmos algumas conexões, reflexões e afirmações referentes ao espaço, ao corpo e aos jovens.

O corpo também é objeto de reflexão de Louro (2004), problematizando este na sua relação com marcas do corpo enquanto marcas de poder. Segundo esta proposta, todo ser humano antes mesmo de nascer, já é marcado enquanto sendo um menino ou uma menina. Todavia, indo além da proposição de Connell (1995), que pensa o 'ser homem' enquanto relacionado a um corpo masculino, entendido enquanto 'biologicamente masculino', corpos não são meramente biológicos, mas socialmente fabricados. Como visto em Louro, "não é o momento do nascimento e da nomeação de um corpo como macho ou como fêmea que faz deste sujeito masculino ou feminino. A construção do gênero e da sexualidade dá-se ao longo de toda a vida, continuamente" (LOURO, 2008, p. 18).

Estas mesmas questões reducionistas são apontadas por Rossi (2011), quando este afirma que autores tem questionado o sistema analítico de Connell (1995), referente a tipologias de masculinidade, segundo atributos e características. Se em Hopkins e Noble (2009) a compreensão da masculinidade deve ir além de simples enumerações de caracteres, ou do estabelecimento de ligações lineares entre caracteres e significados, para Van Hoven e Hörschelmann (2005), podemos considerar as masculinidades como constituídas segundo relações entre práticas, significados, valores, contextos e lugares, em relação complexa.

Outro caminho de discussão apoia-se na própria proposta de Butler (2006), quando esta afirma que o $e u$ sempre está relacionado a constituição das normas, que são imbricações temporais e espaciais. Segundo a imaginação propiciada pela autora, podemos afirmar que a relação entre práticas de masculinidade e normas de masculinidade também orientam-se de forma transformadora. O que entendemos por 
masculinidade não pode ser reconhecido fora destas mesmas normas que estabelecem o que é a masculinidade. Assim, quando a prática de masculinidade é incorporada pela norma, torna-se inteligível através dela, pois não se pode viver e ser reconhecido sem se possuir tais características. Paradoxalmente, os mesmos elementos que produzem o reconhecimento transformam vidas em não habitáveis.

Para Butler (2003), as práticas culturais que classificam os corpos a partir de suas características físicas vão exigir um conjunto de práticas condizentes as normas que regulam estes corpos. Neste caminho, a autora desconstrói uma possível naturalidade, pois sua argumentação aponta para o fato de que há uma construção cultural que funciona segundo a classificação dos corpos segundo suas características físicas de macho ou fêmea. Este sistema de classificação pode ser denominado enquanto mecanismo de gênero, que regula as práticas humanas e cria ficções de feminilidades e masculinidades enquanto naturais. Assim, o gênero vai além de um conjunto de ideias que uma cultura específica constrói em relação ao que é ser homem ou mulher, mas funciona enquanto um mecanismo que é alimentado por discursos médicos, jurídicos, biológicos e teológicos. Pensando que este mecanismo dialoga com a relação entre sexo, gênero, prática sexual e desejo, e que coloca o sexo enquanto pré-discursivo, como dado, anterior a cultura, a partir da heterossexualidade compulsória propõe que o gênero descende do sexo, e a prática sexual e o desejo descendem tanto do sexo quanto do gênero.

Nesta perspectiva, não podemos pensar em gênero antes de problematizar a identidade de gênero. $\mathrm{O}$ funcionamento deste mecanismo produz tanto identidades de gênero inteligíveis - onde existe uma correspondência linear entre sexo, gênero, prática sexual e desejo, quanto identidades de gênero ininteligíveis, onde esta correspondência é inexistente. Podemos, segundo esta reflexão, afirmar que variadas masculinidade são possíveis, tanto naquilo que chamamos de identidade de gênero inteligível quanto ininteligível.

Devemos pensar que estes processos ocorrem segundo a participação de sujeitos ativos, não segundo formas de submissão. A construção de masculinidades é tanto produzida como envolvida pelas práticas sociais, estabelecendo diálogos entre negociações cotidianas e constrangimentos hegemônicos, pois segundo as palavras de Butler (2003): 
o gênero não deve ser construído como uma identidade estável ou um locus de ação do qual decorrem vários atos; em vez disso, o gênero é uma identidade tenuemente constituída no tempo, instituída num espaço externo por meio de uma repetição estilizada de ato (BUTLER, 2003, p. 200).

Sendo assim, é possível, como afirmado por Silva e Ornat (2011), que existam masculinidades em corpos femininos e feminilidades em corpos masculinos. Contudo, nesta discussão, produzimos inteligibilidade sobre as formas de construção de masculinidades em alunos jovens de 14 a 16 anos, que correspondem a identidades de gênero inteligíveis, integrantes da Escola de Guardas Mirins, na sua relação com o espaço.

Este período de transição para fase adulta foi estudado por Valentine (2003), a qual afirma que esta fase é difícil de ser definida até mesmo na esfera da legalidade, tendo delimitação espacial estabelecidas pela idade. No entanto, muitas crianças demonstram maturidade incrível na gestão da sua vida e dos outros, enquanto que muitos adultos se comportam de forma irracional e irresponsável (STABLES e SMITH, 1999 apud VALENTINE, 2003). Na convivência com alunos e alunas da Escola de Guardas Mirins pudemos conhecer um menino de sete anos, o qual é componente de uma família monoparental feminina, vivendo apenas com a mãe que trabalha o dia todo. Como registrado em diário de campo, este menino cotidianamente chegava em casa após as 17 horas, se alimentava com a comida que havia sido preparada anteriormente pela mãe e se recolhia para dormir antes que a mãe tivesse chego do trabalho. Logo pela manhã, antes de ir à escola, tinha a responsabilidade de acordar a mãe. Desta forma, existe pouca correspondência entre a categoria 'adulto' e a idade, pois dependendo da relação espacial, como tratado por Valentine (2003), as pessoas podem ter comportamentos jovens ou adultos, na relação entre faixa etária e responsabilidade contratada. Perante isto, podemos afirmar que salvo algumas regularidades temporais, o que é ser jovem ou adulto está relacionado ao contexto.

Grupos de jovens também foram problematizados por Rossi (2010). Nesta discussão, a vivência de jovens era constituída por paradoxos, pois se em certas circunstâncias estes eram submissos aos jovens mais velhos, em outras situações os jovens, a partir dos elementos relacionados a espera de igualdade, a força bruta e a 
imposição do respeito, podiam investir contra os adolescentes com mais idade que outrora os oprimiam. O que é demonstrado pelo grupo estudado por este autor é a relação da idade com a força, diferentemente da responsabilidade demonstrada pelos alunos jovens da Guardas Mirins.

Procurando evidenciar que as 'autoridades' da sociedade criam e implementam regras determinadas pela idade, Massey (2005) afirma que esta ação está relacionada ao ordenamento espacial da população. Este ordenamento protege o próprio Estado-nação de contravenções sociais endógenas. No Brasil, o Estatuto da Criança e do Adolescente (ECA) estabelecido pela Lei $\mathrm{n}^{\circ} 8.069$ de 13 de julho de 1990, procura definir através do seu Art. $2^{\circ}$, que uma criança é uma pessoa com até doze anos de idade incompletos, e que um adolescente é uma pessoa com idade contida entre o intervalo dos doze aos dezoito anos de idade.

Outros aspectos sobre o ECA, relacionados ao funcionamento da Escola de Guardas Mirins, foram evidenciado pela fala da presidente desta instituição (entrevista realizada em 2/8/2013). Segundo ela, o nascimento do ECA fora importante na medida em que esta legislação definia tanto direitos quanto deveres dos jovens, e que existia um elemento muito importante, relacionado a proibição do trabalho. Todavia, esta proibição, tomada em seu extremo, era prejudicial, pois a ocupação dos jovens era uma estratégia muito produtiva, diminuindo a probabilidade dos jovens realizarem ações que estivessem relacionadas à conflitos com a lei.

Neste relato, dentre as atividades cotidianas que ocorrem na Escola de Guardas Mirins estão a ordem unida - treino de marchas militares e de desfiles cívicos, a partir de movimentos em harmonia, com cadência equilibrada, e o exercício da moral e cívica - relacionada a atividade diária do canto do Hino Nacional, do Hino do Paraná e do Hino de Ponta Grossa, com o hasteamento das respectivas bandeiras. Neste caminho, segundo Rodrigues e Filho (2012) uma espécie de espírito cívico fora imposto pelo Decreto-lei $\mathrm{n}^{\circ} 869$, de 12 de setembro de 1969. Este decreto incluía a Moral e Cívica como disciplina obrigatória em toda a estrutura educacional brasileira. Esta imposição permaneceu até 1993 , sendo revogada pela Lei $n^{\circ}$ 8.663. Salientamos que esta prática tem como tripé o culto a nação, a sua identificação com a família e a dignidade do trabalho.

Os aspectos do militarismo, ou do que podemos chamar de pré-militarismo, é 
feito segundo o treino da disciplina, não segundo o exercício de punições, como nas forças armadas, mas a partir de ações sutis e cotidianas, invisibilizando, como tratado por Foucault (1988), o reconhecimento das próprias relações de poder. Nesta perspectiva, a mais eficaz forma de relação de poder é aquela que não se coloca enquanto relação de poder, pois é invisível.

Foucault (1987), discutindo o funcionamento da disciplina, afirma que ela obteve melhores resultados na imposição do respeito a regras, efetuando conexões à hierarquia. Com isto, pode ser efetuado um maior controle das pessoas. Isto é tão efetivo que como evidenciado em diário de campo (registro realizado em 2/8/2013), no funcionamento da lanchonete da Escola de Guardas Mirins não existe a utilização de dinheiro. A moeda utilizada refere-se a pontos que cada aluno vai adquirindo quando respeita a disciplina e a hierarquia.

Outras duas características da escola advindas do militarismo, na relação com a construção das masculinidades, devem ser tratadas. A primeira diz respeito a cidadania, que alimenta as Forças Armadas, bem como às Polícias Militares e Corpo de Bombeiros. Segundo o próprio Manual do Guarda Mirim (2012) registra-se que esta cidadania forjaria o caráter dos discentes assistidos pela instituição, produzindo futuramente para estes uma convivência 'digna' dentro da sociedade brasileira. A segunda se refere a hierarquia militar, que se coloca como uma classificação e se manifesta na Escola de Guardas Mirins, indo desde o aprendiz mirim ao capitão ou capitã (34\% dos discentes referem-se a meninas). Organizada de forma semelhante àquilo que é discutido por Foucault (1987), a organização hierárquica é piramidal, com funcionamento em rede de cima para baixo. Também se colocando ao inverso e lateralmente, sustentando o conjunto e perpassando os efeitos de poder, sendo os fiscais perpetuamente fiscalizados, mesmo que se coloquem como 'superiores' nas relações de poder.

Não obstante, essa hierarquia não se coloca como fixa, seja através de tempo e espaço, se considerarmos que os corpos carregam marcas da cultura, seja pela idade, gênero, raça ou classe social. Observando então duas ou mais hierarquias conjunturalmente, temos um espaço paradoxal, ou seja, o espaço que seria cartografado exclusivamente em um mapa bidimensional com centro e margem, insider e outsider, são ocupados simultaneamente, como proposto por Rose (1993). Então podemos ter 
uma menina posicionada no centro ou como superior nas relações de poder, tendo em vista sua hierarquia pré-militar e simultaneamente na margem, pelo fato de ser um corpo feminino que é compreendido em uma determinada cultura como inferior em relação a corpos masculinos.

Oposto a este posicionamento e legitimando o patriarcado, a proposta de Connell (1995) demonstra que tanto homens quanto mulheres em suas práticas cotidianas reforçam a supremacia masculina e oportuniza a afirmação da masculinidade hegemônica nas mais variadas relações. Fazendo uso deste conceito, Johnson (2010) procura analisar a construção de uma masculinidade hegemônica militar e suas relações de poderes inerentes. Estas são construídas para meninos e meninas em uma escola quartel no sul da California. Este autor procura demonstrar que a masculinidade e o militarismo são uma construção histórica e estão ligados a uma relação simbiótica. Outro aspecto do trabalho de Johnson (2010) se refere ao aumento das escolas públicas norte americanas, ligadas à militarização, acrescentando que são poucos os trabalhos que buscam desvendar o impacto do militarismo e da militarização na construção de gênero, principalmente das masculinidades.

Em outra perspectiva Ashe (2012) explorou a escassez de pesquisas sobre o conflito étnico-nacionalista na região da Irlanda do Norte e seus processos mais recentes de transformação, relacionando às masculinidades militarizadas e ao poder atribuído a estas. Higate (2007) verifica formas grosseiras de masculinidades militares, moldadas pela estrutura socioeconômica, incrementadas pela impunidade e pelos privilégios, que praticam a exploração sexual em missões de manutenção de paz. Vieira (2011) procura efetuar a desconstrução do modelo de masculinidade militar hegemônica presente no contexto das guerras coloniais de Portugal, trazendo situações de formas específicas de socialização de jovens militares, atos de violência sexual e conflitos interiores movidos pelas críticas envolvendo colonizados e colonizadores, à concepção das masculinidades hegemônicas militarizadas.

Outro autor que nos chama a atenção para as masculinidades militarizadas é Hale (2008; 2012). No primeiro estudo Hale (2008) busca evidenciar como as masculinidades militares são construídas a partir de recursos simbólicos pertencentes às instituições militares. Neste trabalho o autor evidencia que os simbolismos militares atraem pessoas, partindo da investida de proporcionar a descoberta do novo, do 
desconhecido. Também revela que o processo de militarização proporciona às mulheres um meio de desenvolver identidades masculinas. Portando, a Escola de Guardas Mirins é um meio e pode ser uma fonte de estudos que relacionem militarismo, masculinidade, meninas ou mulheres.

No estudo decorrente, Hale (2012) explora as maneiras pelas quais os militares recriam ou reformulam masculinidades, a fim de atingir os objetivos do processo de militarização. $\mathrm{O}$ autor demonstra em seu trabalho que a relação entre militarismo e masculinidade é reciproca, considerando múltiplas masculinidades ao evidenciar que pesquisas mostram que as construções de masculinidades diferem de acordo com a organização em que se está imersa. Sendo os militares construtores de masculinidades distintas, através das práticas militares, estas são consideradas pelo autor como relações mútuas, com combinações complexas de poder e dependência, sucesso e fracasso, resistência e conformidade.

Segundo este autor, a conjuntura de componentes no militarismo assemelhasse a 'comunidade na prática' (WEGNER, 1998 apud HALE, 2012) estabelecendo uma conexão entre dificuldades e especializações. As primeiras minimizadas e as posteriores fortalecidas. Assim, o individuo passa a viver o espaço do outro, seja pelo fortalecimento de suas especialidades, ou pela minimização de suas dificuldades.

Se pensarmos em masculinidades desta forma, devemos salientar que elas são construídas pelas pessoas, segundo as relações nas quais ela é participante, independente de ser menino ou menina, dependendo do posicionamento destas pessoas nestas relações, seja em grande ou pequena escala geográfica, seja na Escola de Guardas Mirins ou na cidade como um todo. Esta relação foi tratada por Foucaut (1984) quando este discute a compreensão da 'heterotopia'. Para o autor, estes seriam locais reais e efetivos, instituídos na relação com a própria constituição da sociedade. Paradoxalmente, colocam-se como contra-locais, possibilidade de realização efetiva das utopias. São espécies de locais que estão fora de todos os outros locais, mesmo que sejam efetivamente localizáveis.

Esta proposição de discussão espacial demanda a reflexão relacionada ao espaço como constituído por inter-relações, instituído segundo multiplicidades sociais e sempre em construção (MASSEY, 2008), segundo sua conexão à proposição de Rose (1999), relacionada a uma forma de pensar o espaço como performático. Segundo esta autora, a 
imaginação geográfica que pensa o espaço enquanto relacional chama a atenção para o fato de que esta relacionalidade não se dá entre sujeitos pré-existentes aos discursos. Portanto, para a autora, pensar o espaço como relacional é analisá-lo como sendo constituído por discursos, fantasias e corporeidades.

Analisar o espaço nesta perspectiva é aceitar o fato de que esta relacionalidade é performada, não elaborada através de essências, mas constituída a partir de interações entre pessoas, na constituição de masculinidades. Esta 'performatividade' relaciona-se à discussão realizada por Butler (2003), na qual esta se refere a ideia do gênero ser um fazer permanente, um texto escrito por um sujeito que não preexiste a escrita. $\mathrm{O}$ espaço a partir desta proposição também se faz segundo um fazer, não existindo um sujeito anterior a esta ação, fazer este relacionado a articulação de performances relacionais a partir das mais variadas espacialidades.

Rose (1999) não entende que o espaço é infinitamente plástico, pois algumas espacialidades são formadas a partir de repetições de relações de poder, como na proposição de Valentine (1993) sobre os espaços heterossexuais. Quando estas espacialidades apresentam-se como não plásticas, é porque a espacialidade das relações foram saturadas por encontros entre o eu e o outro, apresentando certa estabilidade, como visto na pequena plasticidade espacial da Escola de Guardas Mirins. Da mesma forma, pensar o discurso geográfico, ou melhor, a concepção das espacialidades produzidas por corporalidades, coloca-se como fundamental, nos termos de Rose (1999). Segundo ela, isso descobre a perspectiva universalista de várias tradições de reflexão geográfica, marcadas por corpos brancos, masculinos, heterossexuais e não deficientes.

Como analisado pela autora, a partir de algumas geógrafas feministas nasce à demanda de pensar outras modalidades textuais diversas, ou seja, a produção de outros corpos. Os corpos podem ser pensados como marcadores de inclusão e exclusão, mas além disso, existem tensionamentos que se afirmam sobre a negação dos corpos que consistentemente significam o eu e o outro, com suas posições de centro e margem. Os corpos nestes trabalhos nunca produzem a mesma coisa. A performance, utilizando dos termos de Butler (2003), são atos interativos entre as pessoas. Butler não afirma que os corpos aguardam uma codificação de macho ou fêmea, masculino ou feminino. Ao contrário, argumenta que os corpos são discursivos, não sendo o sexo a base da 
sexualidade, rejeitando a autora as afirmações de que ha um outside dos discursos ou um 'antes' simbólico, do tipo que se apresente.

Portanto, os corpos anatomizados e sexuados são a consequência de discursos sobre a heterossexualidade, produzindo corpos masculinos e femininos como seus fundamentos aparentes. Segundo Rose (1999), Butler trata que a existência performativa discursiva dos corpos sexuados é obliterada pelo que ela denomina como efeito substancializante, ou seja, tornar-se substância. As pessoas não são determinadas pelos papéis através dos quais são geradas, porque os processos de significação não são atos de fundação, mas processos regulatórios de repetição que ao mesmo tempo impõe regras e as escondem. Este processo de substancialização materializa as diferenças de corpos sexuados, estabilizando estes ao longo do tempo, produzindo fronteiras e fixidez.

Finalmente, pensar as espacialidades como compostas por fantasias refere-se à discussão que Rose (1999) realiza com De Lauretis (1994). Segundo Rose, De Lauretis pensa o desejo como uma articulação espacial, como uma relação entre diferenças. Este desejo é uma direção em relação ao outro, um caminhar em direção a algo que esta fora de si, ou fora do cotidiano vivido em determinadas espacialidades, apresentado esta proposição uma conexão muito produtiva com a heterotopia foucaultiana. Desta forma, De Lauretis propõe uma relação entre a articulação de diferenças espaciais e sexuais, e o desejo. Rose propõe que a fantasia é pensada enquanto um espaço imaginado, um elemento do desejo. Portanto, os desejos e as fantasias podem desregular discursos, deformando e deslocando espacialidades, fantasias estas imaginadas sempre segundo sinais culturais disponíveis, e como nesta discussão, relacionada às masculinidades.

Para Rose (1999) o corpo é entrelaçado com as fantasias e com os discursos, fantasia esta que é mobilizada nos corpos e expressa através de discursos. Da mesma forma, os discursos são interrompidos pelas fantasias e pelas corporeidades, articulando-se todas estas relações de forma espacial. Para a autora, esta forma de compreensão parece útil, tanto para as formas complexas de se pensar as espacialidades, quanto como uma maneira de se pensar, de se sonhar e de se praticar outras espacialidades estruturadas a partir de distintos caminhos de se produzir relações de diferença.

A complexidade acima apresentada novamente conecta-se a outra proposição, relacionada ao espaço paradoxal de Rose (1993). Segundo a autora, as múltiplas 
possibilidades de existência pessoal apontam para a instituição de espacialidades multidimensionais, sempre contingentes e em movimento, pois o que seria convencionalmente cartografado a partir de posições de centro e margem, ou de insider e outsider, existem simultaneamente, constituindo espacialidades paradoxais, estando as pessoas em dois locais ao mesmo tempo, através dos discursos.

Para Rose (1993), este espaço paradoxal é evidenciado com relativa frequência dentro das Geografias Feministas. Estes trabalhos têm pensado que a conexão entre pontos de partida e destino são perpétuas intersecções destas duas possibilidades. Para a autora, esta visualização das espacialidades implica uma ultrapassagem radical às geometrias heterogêneas, pois possuem sentidos, são vividas, experimentadas e articulam elementos de poder e identidade, colocando-se enquanto geometrias nãoeuclidianas que tratam de relações de poder, de resistência e de reconhecimento das diferenças.

Assim, para Rose (1993), a reflexão sobre esta geografia não pode ser resumida ao simples mapeamento de relações de poder sobre espacialidades. A partir de uma multiplicidade de dimensões se produzem geografias paradoxais, posições estas não imaginadas como sendo constituídas por corpos ocupando várias espacialidades, mas ocupando simultaneamente polos de centro e margem de relações de poder a partir das mais variadas possibilidades espaciais.

Como evidenciado nas respostas de campo, cada espacialidade é diferenciada entre centro e margem de relações de poder na relação com o outro, não sendo este outsider exterior ao discurso do mesmo, pois posições de insider e outsider são simultâneas, havendo uma oscilação entre ambas as posições. Da mesma forma, esta situação paradoxal coloca-se na simultaneidade entre hierarquia e sentimento de igualdade.

Se na vivência da Escola de Guardas Mirins existem relações hierárquicas militares entre os alunos - posição do aprendiz a do capitão - esta configuração produz nestes alunos um sentimento de igualdade, pois caso respeitem o funcionamento da hierarquia, esta abre-se a participação de todos e todas. Assim, na próxima sessão abordamos a relação entre as variadas possibilidades de vivência espacial experimentadas pelos jovens alunos da Escola de Guardas Mirins, instituídos e instituintes de masculinidades. 


\section{Escola de Guardas Mirins e Masculinidades}

Como exposto anteriormente, a Escola de Guardas Mirins 'Tenente Antônio João', da cidade de Ponta Grossa- Paraná, teve como precursor o ferroviário aposentado e hoje diretor da instituição, Sr Epaminondas Xavier de Barros. Quando este se iniciou na prática religiosa espírita, tomou para si a responsabilidade, nos idos de 1965, de retirar 15 meninos que estavam detidos na 'Cadeia Pública' da cidade de Ponta Grossa, contando com a colaboração da Polícia Militar, Bombeiros, Rotarianos e Maçons. Estes últimos cederam inicialmente a Loja Maçônica 'Amor e Caridade' para que os meninos que anteriormente estavam efetuando pequenos furtos e 'invadindo' domicílios na cidade tivessem um local para se estabelecer e receber o apoio necessário, formação e reintegração à sociedade (BARROS, 1999). O fato anteriormente relatado é a semente original da criação do Instituto Educacional 'Duque de Caxias', no mesmo ano do ocorrido, baseado na filosofia e na doutrina espírita, complexificando ainda mais o fenômeno eleito para esta reflexão. Atualmente o Instituto Educacional 'Duque de Caxias' é um grande guarda-chuva, composto pelas seguintes unidades departamentais:

Tabela 1. Temporalidade de Constituição do Instituto Educacional 'Duque de Caxias', Ponta Grossa, Paraná.

\begin{tabular}{|c|c|c|}
\hline Fundação & Unidade Departamental & Público Alvo \\
\hline Julho de 1965 & $\begin{array}{c}\text { Escola de Guardas Mirins 'Tenente } \\
\text { Antônio João' }\end{array}$ & $\begin{array}{c}\text { Pessoas de } 6 \text { a } 18 \text { anos de } \\
\text { idade }\end{array}$ \\
\hline Novembro de 1975 & Casa Assistencial Espírita Nosso Lar & $\begin{array}{c}\text { Pessoas com até } 6 \text { anos de } \\
\text { idade }\end{array}$ \\
\hline Setembro de 1981 & $\begin{array}{c}\text { Aldeia Espírita da Criança 'Dr. } \\
\text { David Federmann' }\end{array}$ & $\begin{array}{c}\text { Meninos com até } 6 \text { anos } \\
\text { de idade / Meninas com } \\
\text { até } 12 \text { anos de idade }\end{array}$ \\
\hline Julho de 1982 & Recanto Espírita 'Maria Dolores' & $\begin{array}{l}\text { Pessoas com Deficiência } \\
\text { Neurológica (até } 12 \text { anos } \\
\text { incompletos) }\end{array}$ \\
\hline Janeiro de 1986 & Creche Espírita 'Tia Sueli' & $\begin{array}{c}\text { Pessoas com até } 6 \text { anos de } \\
\text { idade }\end{array}$ \\
\hline Outubro de 1994 & Esperança Cidade dos Meninos & $\begin{array}{c}\text { Meninos dos } 7 \text { aos } 18 \\
\text { anos }\end{array}$ \\
\hline
\end{tabular}

Geo UERJ. Rio de Janeiro - Ano 16, no. 25, v.2, $2^{\circ}$ semestre de 2014, pp.142-171

ISSN: 1415-7543 E-ISSN: 1981-9021

http://www.e-publicacoes.uerj.br/index.php/geouerj 


\begin{tabular}{|c|c|c|} 
Fevereiro de1995 & Lar Espírita 'Odilon Mendes' & $\begin{array}{c}\text { Homens com Deficiência } \\
\text { Neurológica (a partir dos } \\
18 \text { anos) }\end{array}$ \\
Agosto de1998 & Creche Espírita 'Ana Neri' & $\begin{array}{c}\text { Pessoas com até 6 anos de } \\
\text { idade }\end{array}$ \\
\hline
\end{tabular}

Fonte: Barros (1999).

Algumas modificações ocorreram no decorrer da história na instituição, tanto em relação a sua localização, quanto ao número e as pessoas atendidas. Exemplo disso é o internato da Escola de Guardas Mirins que deixa de existir gradativamente, passando a atender as crianças e adolescentes no contra turno escolar. Outra mudança refere-se a garantia de vaga na Escola de Guardas Mirins para àquelas crianças que estiveram matriculadas nas creches sob responsabilidade do Instituto Educacional 'Duque de Caxias'. Uma das alterações que são deveras importante para a presente discussão refere-se ao fato de que desde a sua fundação, a Escola de Guardas Mirins atendia exclusivamente meninos, passando a atender meninas a partir do ano de 1976, apenas onze anos depois de sua fundação.

Podemos afirmar, segundo a análise de todo o material empírico levantado no processo de pesquisa, que a Escola de Guardas Mirins tem suas atividades lastreadas em três trinômios metodológicos, a saber: Metodológico Social, Metodológico Histórico e o Metodológico Moral.

O primeiro trinômio é composto pelos elementos 'estudar, trabalhar e progredir'. Estes três elementos colocam-se, para os alunos e alunas da Escola de Guardas Mirins, enquanto um horizonte a ser atingido. Estão tão presentes no cotidiano desta escola que as palavras 'estudar, trabalhar e progredir' fazem parte do brasão da instituição, como visto na figura abaixo: 


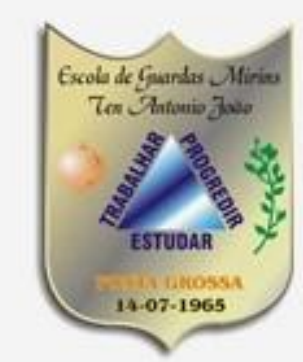

Figura 1. Brasão da Escola de Guardas Mirins 'Tenente Antônio João', Ponta Grossa, Paraná.

Segundo anotações de caderno de campo, um dos componentes da administração afirmou que, as três palavras acima citadas estão posicionadas fora do triângulo, que simboliza perfeição, de cor azul, que representa o infinito. Estas palavras também estão entre duas figuras. A direita da figura localiza-se um romã, que representa a união, e na esquerda existe um ramo de acácia, que segundo a mesma proposição, representa a pureza, além de ser um dos símbolos por excelência da maçonaria. Finalmente, a cor amarela do matiz de fundo da figura está relacionado a evolução, novamente lastreandose ao espiritismo kardecista.

O segundo trinômio desta compreensão não é tão evidente quanto o anterior, mas igualmente importante. Este diz respeito ao metodológico histórico, constituído pelos elementos 'igualdade, liberdade e fraternidade', palavras observada tanto na proposição de Barros (1999), quanto nas categorias discursivas que compõe as falas dos alunos entrevistados.

O último trinômio é constituído pelos elementos 'disciplina, hierarquia e a evangelização cristã'. Os dois elementos iniciais compõe o simbolismo do militarismo, como já observado por Hale (2008), enquanto o terceiro elemento tem relação com o cristianismo. A evangelização cristã, advinda do espiritismo kardecista, é facultada pelas leis morais, que são, segundo Rivas (2009), as leis divinas e naturais, correspondendo a Lei de Adoção, Lei do Trabalho, Lei de Reprodução, Lei de Conservação, Lei de Destruição, Lei de Sociedade, Lei de Progresso, Lei de Igualdade, Lei de Liberdade e a Lei de Justiça, de Amor e de Caridade, todas elas voltadas à humanidade. Nesta perspectiva, a 'moral' seguida pelos alunos da Escola de Guardas Mirins está relacionada aos elementos que constituem a prática religiosa espírita kardecista, referente "a regra de bem proceder, isto é, de distinguir o bem do mal. 
Funda-se na observância da lei de Deus. O homem procede bem quando tudo faz pelo bem de todos, porque então cumpre a lei de Deus" (KARDEC, 2004, p. 383).

Chamamos a atenção para a situação de que através do discurso da Escola de Guardas Mirins, esta evangelização cristã adquire uma faceta relacionada ao espiritismo kardecista. A instituição não tem a pretensão de formar, em seus alunos e alunas, futuros espíritas e/ou militares. Contudo, afirmamos que somos o que somos pelas mais variadas influências que recebemos ao longo da vida, pois como tratado por Guareschi (2006, p. 40), o ser humano é visto enquanto um ser que vai se fazendo "a partir das relações que vai estabelecendo com os outros seres humanos. (...) sua subjetividade é composta dos milhões de relações que ele estabelece durante toda sua existência.

Os outros dois elementos do pilar 'moral' da Escola de Guardas Mirins apoiamse naquilo que é proposto por Foucault (1987), referente as práticas de vigilância e punição. O autor demonstra métodos utilizados desde o século XVII que "permitem o controle minucioso das operações do corpo, que realizam a sujeição constante de suas forças e lhes impõem uma relação de docilidade-utilidade, são o que podemos chamar as 'disciplinas"'.(FOUCAULT, 1987, p.126).

Parafraseando Foucault (1987), o exercício de vigilância não ocorre com punições, nem com a intensidade da força dos órgãos militares do Estado. A Escola de Guardas Mirins repreende com micropenalidades, faltas relativas ao tempo (atrasos, ausências, interrupções das tarefas), a atividade (desatenção, negligência, falta de zelo), a maneira de ser (grosseria, desobediência), o excesso de discursos (tagarelice, insolência), ao corpo (atitudes 'incorretas', gestos não conformes, vestimentas), a sexualidade (imodéstia, indecência).

Tais ações levam a perda de pontos que os alunos e alunas adquirem, por empréstimo, quando do ingresso na escola. Estes iniciam suas atividades com um crédito de 30 pontos. Cada transgressão é punida com a perda de pontos. Quando estes se esgotam, há o desligamento do aluno ou aluna da instituição. Por outra direção, quando os alunos e alunas realizam atividades de bom comportamento, dedicação, respeito a hierarquia, participação em eventos, etc, os alunos e alunas adquirem novos pontos a serem somados ao inicial, quando do ingresso. Assim, como visto em Foucault (1987), a punição, na disciplina, é um sistema duplo com gratificação e sanção.

Frente a conjuntura de elementos que constituem a Escola de Guardas Mirins, o 
número de pessoas constantes na lista de espera a vagas é de 1.723 pedidos (dados extraídos do Banco de Dados em 06/2013). Este volume está distribuído em três grupos: 'aguardando' (47,7\%), 'cancelados' (33,5\%) e 'inclusos' (18,8\%). As proporções foram divididas entre meninas e meninos, totalizando um terço para meninas e dois terços para meninos, tanto para o total de pessoas a espera de vaga como para os grupos subjacentes.

Os dados familiares da lista de espera evidenciam que dentre estas, predominam as famílias que vivenciaram dissolução conjugal (85.5\%). Também em relação ao total de cadastros da lista de espera, 85\% deles referem-se a famílias monoparentais femininas. Em relação a ocupação, quando o pai está presente, este representa $21.4 \%$ das ocupações na construção civil. Em relação a mãe, $43.3 \%$ tem ocupação referente ao trabalho doméstico. Assim, podemos afirmar que das famílias que procuram a Escola de Guardas Mirins, os maiores percentuais tem por característica mães com a função do cuidado com os filhos, com a casa e se responsabilizando pela reprodução econômica do lar. Devido a característica da baixa instrução e experiência profissional, ocupam-se de trabalhos domésticos em casas de terceiros. Novamente, em relação ao total, os motivos da busca por apoio social na instituição foram agrupados em: 'para não ficar sozinho(a)' (35,0\%); 'para ter uma ocupação' (13,0\%); 'aprendizado / educação / ensino' (12,0\%); 'não ficar pela rua' (11,6\%); 'quer entrar na Escola de Guardas Mirins' (8,5\%); 'trabalho / profissão' (3,8\%); 'disciplina' (3,4\%); 'melhor futuro' (2,6\%); 'prevenir ou distanciar das más companhias' (2,4\%); 'benefícios da Escola de Guardas Mirins' $(2,4 \%)$; 'dificuldade familiar' (2,0\%); 'cursos' (1,6\%); 'encaminhado do conselho tutelar' $(1,1 \%)$.

Estes dados evidenciam que a busca pela instituição se da a partir da vulnerabilidade social em que encontram-se crianças e adolescentes. Assim, as famílias que procuram a instituição, afim de consegui vagas aos seus filhos, pretendem que a Escola de Guardas Mirins colabore para que os meninos não exerçam em um curto período de tempo atos infracionais, correspondendo àquilo que Rossi (2010) denomina enquanto uma 'masculinidade periférica', para se referir ao exercício que se choca ao ideal socialmente construído para o ser homem.

Assim, como visto acima, o complexo metodológico - social, histórico e moral tem sido eficaz em uma prática educativa que é direcionada ao treino cotidiano de 
alunos e alunas em relação à práticas distanciadas de possíveis masculinidades periféricas. Chamamos a atenção para o fato de que estas práticas não estão pairando como nuvens acima das cabeças das pessoas. Pelo contrário, compõe espacialidades, assim como são por elas compostas. Em suma, este complexo metodológico é uma prática espacial, que se faz válida e eficaz através da Escola de Guardas Mirins, espraiando-se para outras espacialidades, segundo a vivência espacial de alunos e alunas desta instituição, salvo nas situações de inadequação comportamental de alguns alunos. Nestas situações, os alunos são convidados a não permanecer mais na Escola de Guardas Mirins.

Os alunos que tem suas solicitações de vaga atendidas totalizam 203 cadastros. Deste total, $35 \%$ são compostos por meninas e $65 \%$ por meninos. Salientamos que estas possuem as mesmas características dos requerentes a vaga, cadastrados na lista de espera problematizada acima. Do total de cadastros de alunos ativos, 92\% dos alunos e alunas estão no período da infância, se considerado que segundo o Estatuto da Juventude (2013), as pessoas que possuem menos que 15 anos estão no período de infância. Os alunos que foram contemplados com vagas na Escola de Guardas Mirins são admitidos nesta instituição em um período, que como visto por Valentine (2003), é instituído por transição, ou melhor, o próprio período é transição. O centro da discussão de Valentine não é a relação entre idade e as classificações de infância e fase adulta, mas sim problematiza a relação entre independência e autonomia enquanto elementos de práticas sociais adultas.

Por outro lado, Jefrey (2010) argumenta que muitas pessoas não chegam a esta possível fase adulta, devido a características socioeconômicas, principalmente no continente africano. Este autor considera a possibilidade de existência de uma juventude permanente, que advém de conjunturas vitais que permitem e/ou limitam a ação social. Esta reflexão evidencia que a vulnerabilidade dos jovens é muitas vezes um produto das transformações nas práticas educacionais, articuladas à outras forças estruturais.

Depois deste momento de discussão que tratou tanto da lista de candidatos a vaga quanto de alunos ativos, passamos a problematizar as informações coletadas através de realização de entrevistas semiestruturadas com meninos alunos da Escola de Guardas Mirins. O recorte de grupo esteve relacionado a utilização de três critérios de escolha de meninos alunos a serem entrevistados: 1. posição de prestígio ocupada pelo 
entrevistado junto ao grupo de jovens; 2. aceitabilidade do sujeito pesquisador junto ao grupo a ser investigado, resultando em um grupo de entrevistados que possuíam idade entre 14 e os 16 anos; 3. maior tempo de vivencia na instituição.

O volume de dez entrevistas fora estabelecido segundo o critério de saturação proposto por Sá (1998). Foram realizadas oito entrevistas e a partir da observação do critério de saturação, executamos outras duas entrevistas finais. Estas falas produziram um total de 4 horas e meia de diálogo, que foram analisadas segundo a proposta de Bardin (1977), referente a análise de conteúdo do discurso. A atividade produziu um total de 268 evocações que foram organizadas segundo as espacialidades discursivas da 'Guarda Mirim' (58,5\% das evocações), 'Espaços de Sociabilidade' (17,4\%), 'Trabalho' (14,7\%), 'Casa' (4,9\%), 'Escola' (3,1\%) e 'Igreja' (1,3\%), constituídos por suas respectivas categorias discursivas. Salientamos que $19 \%$ do total de evocações não serão problematizadas devido ao fato de não terem constituído categoria 'espacialidade discursiva', resultando em análise. Assim, vejamos a configuração total resultante da análise do conteúdo do discurso destes meninos jovens:

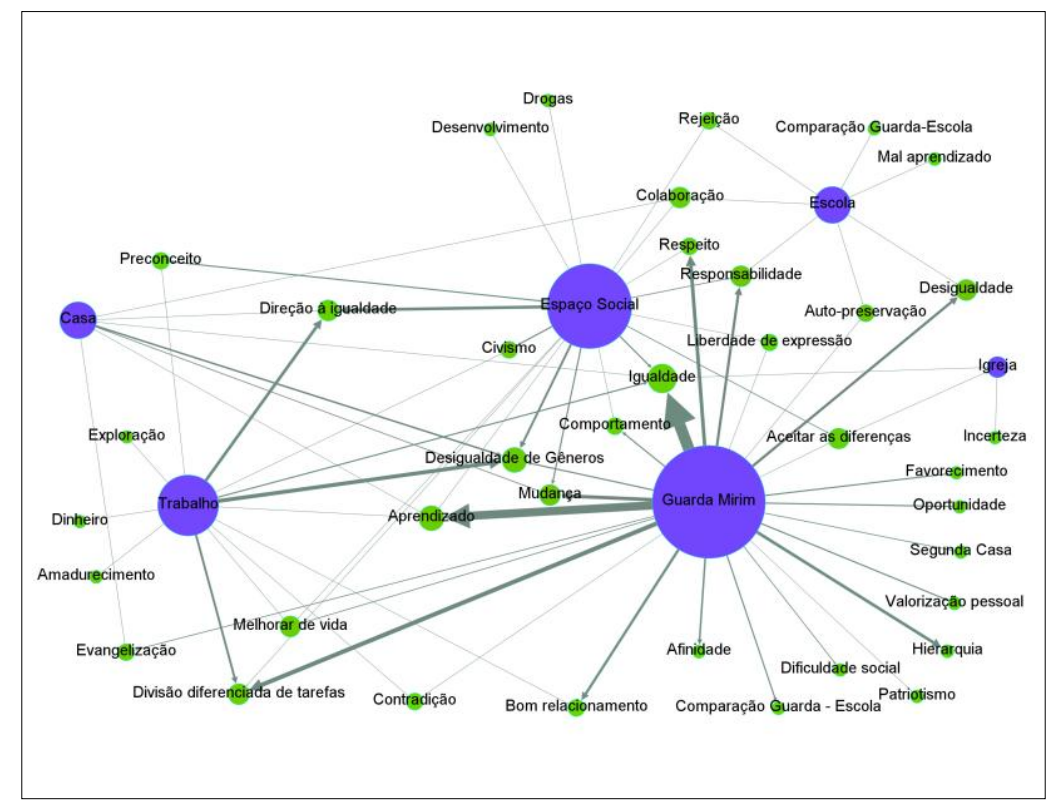

Figura 2. Configuração total da Análise de Conteúdo do Discurso dos Meninos Alunos da Escola de Guardas Mirins, em Ponta Grossa, Paraná.

Iniciamos nossa discussão pela espacialidade discursiva majoritária, relacionada a 'Guarda Mirim'. O grande percentual relacionado a esta espacialidade deve-se ao fato dos objetivos propostos para a presente reflexão. Todavia, nos cabe construir uma 
reflexão sobre as categorias discursivas que constituem esta espacialidade discursiva, relacionadas a: 'Igualdade' (19,1\%), 'Aprendizado' (14,5\%), 'Divisão diferenciada de tarefas' (7,6\%), 'Mudança' (6,1\%), 'Respeito' (6,1\%), 'Hierarquia' (5,3), 'Bom Relacionamento' (4,6\%), 'Desigualdade' (4,6\%), 'Responsabilidade' (4,6\%), 'Afinidade' (3,1\%), 'Comparação Guarda - Escola' (2,3\%), 'Comportamento' (2,3\%), 'Desigualdade de Gênero' (2,3\%), 'Favorecimento' (2,3\%), 'Oportunidade' (2,3\%), 'Valorização pessoal' (2,3\%), 'Dificuldade social' (1,5\%), 'Evangelização' (1,5\%), 'Melhora de vida' (1,5\%) e 'Segunda casa' (1,5\%) (4,8\% deste grupo não compuseram categoria discursiva).

O conjunto de categorias discursivas atribuídas à Escola de Guardas Mirins estão em maior parte relacionadas as metodologias aplicadas por ela (Estudar, Trabalhar e Progredir; Disciplina, Hierarquia e Evangelização Cristã; Igualdade, Liberdade e Fraternidade). Não afirmamos que estes elementos são exclusivos da espacialdiade da Guarda Mirim. Contudo, como evidenciado acima, são elementos de seu funcionamento. Os elementos referentes a divisão diferenciada de tarefas, desigualdade, desigualdade de gênero e dificuldade social tem relação na vivência destes jovens homens a idade, ao tempo na instituição, situação social e relações assimétricas entre meninos e meninas.

A segunda espacialidade discursiva com maior volume se refere ao 'Espaços de Sociabilidade' com 17,4\% das evocações, estando relacionada as seguintes categorias discursivas: 'Direção à igualdade' (17,9\%), 'Desigualdade de gênero' (15,4\%), 'Preconceito' (7,7\%), 'Mudança' (7,7\%), 'Igualdade' (7,7\%), 'Civismo' (7,7\%), 'Aceitar as diferenças' (5,1\%), 'Responsabilidade' (5,1\%), 'Respeito' (2,6\%), 'Rejeição' (2,6\%), 'Melhora de vida' (2,6\%), 'Liberdade de expressão' (2,6\%), 'Drogas' (2,6\%), 'Divisão diferenciada de tarefas' (2,6\%), 'Desenvolvimento' (2,6\%), 'Comportamento' (2,6\%), 'Colaboração' (2,6\%) e 'Aprendizado' (2,6\%).

Em relação as categorias discursivas acima expostas, as falas dos jovens homens entrevistados evidenciam uma diminuição da assimetria entre meninos e meninas. Não obstante, para os alunos ainda é clara a diferença entre mulheres e homens na sociedade. As falas evidenciam um processo de amadurecimento, como discutido por Valentine (2003). Por isso, a responsabilidade ganha prestigio entre os discentes da instituição em outras espacialidades, considerando a diversidade de pessoas que compõe sua vivência social. 
A terceira espacialidade discursiva mais encontrada nas falas dos alunos é o 'Trabalho', com 14,7\% das evocações, estando relacionada as categorias discursivas: 'Desigualdade de gênero' (27,3\%), 'Direção à igualdade' (21,2\%), 'Divisão diferenciada de tarefas' (15,2\%), 'Igualdade' (9,1\%), 'Aprendizado' (3,0\%), 'Preconceito' (3,0\%), 'Melhorar de vida' (3,0\%), 'Exploração' (3,0\%), 'Dinheiro' (3,0\%), 'Contradição' (3,0\%), 'Civismo' (3,0\%), 'Bom relacionamento' (3,0\%) e 'Amadurecimento' (3,0\%).

Chamamos a atenção de que, entre os aspectos relacionados ao trabalho, destacado pelos entrevistados, esta a distinção entre as ocupações de mulheres e homens, mas que demonstram uma possível igualdade futura. Outros elementos do trabalho se referem a mudança individual adquirida através dos aprendizados, quanto ao significado deste nas conquistas pessoais e melhoria de vida de cada um.

A 'Casa' aparece como a quarta espacialidade discursiva analisada, com 3,1\% do total de evocações, constituído pelas categorias discursivas 'Desigualdade de gênero' (36,4\%), 'Mudança' (18,2\%), 'Aprendizado' (9,1\%), 'Colaboração' (9,1\%), 'Direção a igualdade' (9,1\%), 'Evangelização' $(9,1 \%)$ e 'Igualdade' $(9,1 \%)$. Os elementos que facultaram estas categorias à esta espacialidade, demonstram que é na casa que os entrevistados observam maior desigualdade entre homens e mulheres. Ainda evidenciam que as demais categorias discursivas sofreram forte influência das intersecções com a Escola de Guardas Mirins, principalmente referente às mudanças que estão ligadas ao comportamento proveniente da convivência com a espacialidade estudada, referente ao aprendizado da igualdade, da colaboração e da evangelização cristã.

A penúltima espacialidade discursiva identificada nas entrevistas se refere a 'Escola' regular, constituída pelas categorias discursivas 'Auto preservação', 'Colaboração', 'Comparação Guarda - Escola', 'Desigualdade', 'Mal aprendizado', 'Rejeição' e 'Responsabilidade', cada uma computando 14,3\% do total da espacialidade discursiva. Com os elementos que atribuíram tais categorias a esta espacialidade, os alunos destacaram a diferença entre a convivência nas escolas regulares e na Escola de Guardas Mirins, na primeira a liberdade de expressão é barrada pela auto preservação, o que vem a limitar o aprendizado, que seria voltado ao momento e não orientado a um aprendizado para a vida, adquirida na Escola de Guardas Mirins. Finalmente, tratamos da espacialidade discursiva 'Igreja', com 1,3\% do total de evocações. Esta esteve relacionada as categorias discursivas 'Aceitar as diferenças' (33,3\%), 'Igualdade' 
(33,3\%) e 'Incerteza' (33,3\%). As duas primeiras estão estreitamente ligadas ao espiritismo kardesista e a terceira relacionada a multiplicidade de igrejas e doutrinas.

O que todo o campo evidencia relaciona-se a um encaminhamento para o ser adulto na conexão com a vivência social e educação. Perante isto, a Escola de Guardas Mirins tem sido muito eficaz em uma possível interrupção do ser criança e adolescente, na cobrança cotidiana de práticas sociais adultas, como visto no trinômio metodológico social - estudar, trabalhar e progredir - e em dois elementos do trinômio metodológico moral, referentes a disciplina e ao respeito a hierarquia. Ou seja, a citada instituição trabalha com objetivos de ir além da mera educação para a transformação de jovens em adultos, mas sim operacionaliza um conjunto de mecanismos educacionais orientados a instituição de jovens que exercitem masculinidades adultas, que distanciem-se de masculinidades periféricas.

\section{Considerações Finais}

O presente texto evidenciou a relação entre espacialidades e a constituição de masculinidades de jovens no cotidiano da Escola de Guardas Mirins 'Tenente Antônio João', na cidade de Ponta Grossa, Paraná. Toda a discussão demonstra que a Escola de Guardas Mirins funciona segundo uma conexão entre militarismo e espiritismo kardecista, funcionamento este orientado a construção de masculinidades de adultos em jovens homens. Estas formas de masculinidade não se colocam enquanto monolíticas, mas sim instituem-se de forma contextual, na relação entre tempo e espaço. Portanto, as masculinidades vivenciadas e exercitadas por alunos da Escola de Guardas Mirins 'Tenente Antônio João' são uma destas possibilidades, vivências estas que dialogam com construções de masculinidade hegemônicas e periféricas.

\section{Referências}

ASHE, Fidelma. Gendering War and Peace: Militarized Masculinities in Northern Ireland. Men and Masculinities, v. 15, p. 230 - 248, 2012.

BARDIN, Laurence. Análise de conteúdo. Lisboa: Edições 70, 2002.

BARROS, Epaminondas Xavier de. Histórias dentro da História. Ponta Grossa: Instituto Educacional Duque de Caxias, 1999. 
BRASIL. Estatuto da Criança e do Adolescente. Lei nº 8.069, de 13 de julho de 1990. BRASIL. Estatuto da Juventude. Lei no 12.852, de 5 de agosto de 2013.

BRASIL. Inclusão da Educação Moral e Cívica. Decreto-Lei $n^{\circ}$ 869, de 12 de dezembro de 1969.

BRASIL. Revoga o Decreto-Lei $n^{\circ}$ 869, de 12 de dezembro de 1969. Lei $n^{\circ}$ 8.663, de 14 de junho de 1993.

BUTLER, Judith. Deshacer el Género. Buenos Aires: Paidós, 2006.

BUTLER, Judith. Problemas de gênero: Feminismo e subversão da identidade. Rio de Janeiro: Civilização Brasileira, 2003.

CHIMIN JUNIOR, Alides Baptista. Espaço, vulnerabilidade e masculinidade de adolescentes em conflitos com a lei. In: SILVA, Joseli Maria; ORNAT, Marcio Jose; CHIMIN JUNIOR, Alides Baptista Chimin. Espaço, Gênero \& Masculinidades Plurais. Ponta Grossa. Toda Palavra, 2011, p. 55 - 124.

CHIMIN JUNIOR, Alides Baptista. O espaço como componente da vulnerabilidade aos atos infracionais desenvolvidos por adolescentes do sexo masculino em conflito com a lei em Ponta Grossa-Paraná. 148 f. Dissertação (Mestrado em Geografia Gestão do Território) - Programa de Pós-Graduação em Geografia, Universidade Estadual de Ponta Grossa, 2009.

CONNELL, Robert; MESSERSCHMIDT, James. Masculinidade hegemonica: repensando o conceito. Estudos Feministas, v. 21, n 1, p. 241 - 282, 2013.

CONNELL, Robert. Políticas da masculinidade. Educação \& Realidade, v. 20, n. 2, p. 185-206, 1995.

COSTA, Benhur Pinós da. Geografias, Masculinidades e Homoerotismo: teorias, práticas e posicionalidades da pesquisa. In: SILVA, Joseli Maria; ORNAT, Marcio Jose; CHIMIN JUNIOR, Alides Baptista Chimin. Espaço, Gênero \& Masculinidades Plurais. Ponta Grossa. Toda Palavra, 2011, p. 329 - 356.

FOUCAULT, Michel. Dits et écrits 1984, Des espaces autres. Architecture, Mouvement, Continuité, n. 5, p. 46-49, 1984.

FOUCAULT, Michel. Vigiar e punir: nascimento da prisão. Petrópolis: Vozes, 1987. FOUCAULT, Michel. História da Sexualidade I: a vontade de Saber. Rio de Janeiro: Graal, 1988.

FURLONG, Anthony. Tolerância das performaces de raça e classe na zona sul entre homens queer do Rio de Janeiro. In: SILVA, Joseli Maria; ORNAT, Marcio Jose; CHIMIN JUNIOR, Alides Baptista Chimin. Espaço, Gênero \& Masculinidades Plurais. Ponta Grossa. Toda Palavra, 2011, p. 225 - 259.

GOMES, Fernando Bertani. 'Cenas Embaçadas': A Relação entre as Espacialidades Vivenciadas por Jovens do Sexo Masculino e a Morte por Homicídio na Cidade de Ponta Grossa, Paraná. 173 f. Dissertação (Mestrado em Geografia - Gestão do Território) - Programa de Pós-Graduação em Geografia, Universidade Estadual de Ponta Grossa, 2013.

GUARESCHI, Pedrinho. Mídia e Cidadania. Conexão - Comunicação e Cultura, v. 5, n. 9, p. 27 - 40, 2006.

HALE, Hannah. The Development of British Military Masculinities through Symbolic 
Resources. Culture Psychology, v. 14, p. 305 - 332, 2008.

HALE, Hannah. The Role of Practice in the Development of Military Masculinities. Gender, Work and Organization, v. 19, n. 6, p. 699 - 722, 2012.

HIGATE, Paul, Peacekeepers, Masculinities, and Sexual Exploitation. Men and Masculinities, v. 10, p. 99-119, 2007.

HOPKINS, Peter; NOBLE, Greg. Masculinities in place: situated identities, relations and intersectionality. Social \& Cultural Geography: Special issue, v. 10, n. 8, p. 811$819,2009$.

JEFFREY, Craig. Geographies of children and youth I: eroding maps of life. Progress in Human Geography, v. 34, p. 496-50, 2010.

JOHNSON, Brooke. A Few Good Boys: Masculinity at a Military-Style Charter School. Men and Masculinities, v. 12, p. 575 - 596, 2010.

KARDEC, Allan. O Livro dos Espíritos. Rio de Janeiro: Ed. Federação Espirita Brasileira. 2004.

LAURETIS, Teresa de. The Practices of Love: Lesbian Desire and Perverse Sexuality. Bloomington: Indiana University Press, 1994.

LOURO, Guacira Lopes. Um corpo estranho - ensaio sobre sexualidade e teoria queer. Belo Horizonte: Autentica. 2004.

MANUAL DO GUARDA MIRIM. Instituto Duque Educacional Duque de Caxias, 2012.

MASSEY, Doreen. KEYNES, Milton. Filosofia e Política da espacialidade: algumas considerações. GEOgraphia. v. 6, n. 12, p. 7 - 23, 2004.

MASSEY, Doreen. Pelo Espaço: Uma nova política da Espacialidade. Rio de Janeiro: Bertrand Brasil, 2008.

MASSEY, Doreen. The Spatial Construction of Youth Cultures. In: SKELTON, Tracey; VALENTINE; Gill. Cool Places. Geographies of youth cultures. London: Routledge, 2005, p. 122 - 130.

MIGNOLO, Walter. Os esplendores e as misérias da 'Ciência': Colonialidade, geopolítica do conhecimento e pluri-versalidade epistémica. In: SANTOS, Boaventura de Souza. Conhecimento prudente para uma vida decente. São Paulo: Cortez, 2004, p. $667-709$.

RATTS, Alex. Negritude, masculinidade, homoerotismo e espacialidade em James Baldwin: uma leitura brasileira. In: SILVA, Joseli Maria; ORNAT, Marcio Jose; CHIMIN JUNIOR, Alides Baptista Chimin. Espaço, Gênero \& Masculinidades Plurais. Ponta Grossa. Toda Palavra, 2011, p. $261-289$.

RIVAS, Luis Hu. Doutrina Espírita Para Principiantes. Brasília: Conselho Espírita Internacional. 2009.

ROCHA, Heder Leandro. Espaço Espiado: O Uso do Crack Instituindo Espacialidades Vivenciadas por Adolescentes do Sexo Masculino em Ponta Grossa, Paraná. 115 f. Dissertação (Mestrado em Geografia - Gestão do Território) - Programa de Pós-Graduação em Geografia, Universidade Estadual de Ponta Grossa, 2013.

RODRIGUES, Elaine; FILHO, Geraldo Inácio. Educação Moral e Cívica e Ensino de História, Aportes 
Disciplinares de Formação: Um estudo comparado. Revista HISTEDBR On-line, n. 45, p. 139 - 152, 2012.

ROSE, Gilian. Feminism \& Geography. The limits of Geographical Knowledge. Cambridge: Polity Press, 1993.

ROSE, Gillian. Performing Space. In: MASSEY, Doreen; ALLEN, John; SARRE, Phillip. Human Geography Today. Cambridge: Polity Press, 1999, p. 247 - 259.

ROSSI, Rodrigo. 'Malucos da Quebrada': territórios urbanos na complexidade espacial cotidiana dos adolescentes homens em conflito com a lei em Ponta GrossaParaná. 233 f. Dissertação (Mestrado em Geografia - Gestão do Território), Programa de Pós-Graduação em Geografia, Universidade Estadual de Ponta Grossa, 2010.

ROSSI, Rodrigo. Masculinidades e interseccionalidade na vivência de territórios instituídos por adolescentes em conflito com a lei. In: SILVA, Joseli Maria; ORNAT, Marcio Jose; CHIMIN JUNIOR, Alides Baptista Chimin. Espaço, Gênero \& Masculinidades Plurais. Ponta Grossa. Toda Palavra, 2011, p. 125 - 191.

SÁ, Celso Pereira de. A construção do objeto de pesquisa em Representações sociais. Rio de Janeiro: EdUERJ, 1998.

SILVA, Joseli Maria (Org). Geografias Subversivas - discursos sobre espaço, gênero e sexualidade. Ponta Grossa: Editora Toda Palavra, 2009.

SILVA, Joseli Maria; ORNAT, Marcio Jose. Espaço e múltiplas masculinidades: um desafio para o conhecimento científico geográfico brasileiro. In: SILVA, Joseli Maria; ORNAT, Márcio José; CHIMIN JUNIOR, Alides Babtista. Espaço, gênero \& masculinidades plurais. Ponta Grossa:Todapalavra, 2011, p. 23 - 54.

SILVA, Joseli Maria; ORNAT, Marcio Jose. Espaço e múltiplas masculinidades: um desafio para o conhecimento científico geográfico brasileiro. In: SILVA, Joseli Maria; ORNAT, Marcio Jose; CHIMIN JUNIOR, Alides Baptista Chimin. Espaço, Gênero \& Masculinidades Plurais. Ponta Grossa. Toda Palavra, 2011, p. 13 - 15.

Souza, Marcelo Lopes de. Às leitoras e aos leitores desassombrados: Sobre o livro Espaço, gênero e masculinidades plurais. In: SILVA, Joseli Maria; ORNAT, Marcio Jose; CHIMIN JUNIOR, Alides Baptista Chimin. Espaço, Gênero \& Masculinidades Plurais. Ponta Grossa. Toda Palavra, 2011, p. 13 - 15.

STABLES, Janes; SMITH, Fiona. 'Caught in the Cinderella trap': narratives of disabled parents and young carers. In: BUTLER, Ruth; PARR, Hester (Eds). Mind and Body Spaces. London: Routledge, 1999, p. 256-268.

VALENTINE, Gill. (Hetero)Sexing Space: Lesbian Perceptions and Experiences of Everyday Spaces. Environment and Planning D: Society and Space, vol. 11, p. 395 413, 1993.

VALENTINE, Gill. Boundary Crossings: Transitions from Childhood to Adulthood. Children's Geographies, v. 1, n. 1, p. 37-52, 2003.

VAN HOVEN, Bettina; HÖRSCHELMANN, Kathrin. Spaces of Masculinities. London: Routledge, 2005.

VIEIRA, Paulo Jorge. (Des)fazer-se homem na guerra: Masculinidades e guerra Colonial em 'Os Cus de Judas'. In: SILVA, Joseli Maria; ORNAT, Marcio Jose; CHIMIN JUNIOR, Alides Baptista Chimin. Espaço, Gênero \& Masculinidades Plurais. Ponta Grossa. Toda Palavra, 2011, p. 291 - 327. 
WENGER, Etienne. Communities in Practice. Learning, Meaning and Identity. Cambridge: Cambridge University Press. 1998.

Artigo recebido para publicação em julho de 2014.

Artigo aceito para publicação em dezembro de 2014. 